\title{
A utilização das Tecnologias da Informação e Comunicação nos projetos educacionais interdisciplinares
}

\author{
Bianca Trindade Baptista1, Márcia de Freitas Vieira² \\ ${ }^{1}$ Instituto Federal do Espírito Santo \\ Rodovia ES-010, Km 6.5, Manguinhos - 29173-087 - Serra - ES \\ ${ }^{2}$ Instituto Federal do Espírito Santo \\ Rodovia ES-010, Km 6.5, Manguinhos - 29173-087 - Serra - ES \\ biancategmail.com, marcia.ipatingaegmail.com
}

\begin{abstract}
This article presents the results of a survey conducted in two public schools, one located in Vila Velha (ES) and another in Vitória (ES), in order to investigate how the information and communication technologies have enhanced student learning when used in interdisciplinary educational projects. The investigation took place from classes developed in the computer labs with the 1st to 5th grade classes between the years 2014 and 2015. As a result of this study concluded that the design methodology when combined with the technology contributes significantly in learning and autonomy of students and their training process.
\end{abstract}

Resumo. Este artigo apresenta os resultados de uma pesquisa realizada em duas escolas municipais, uma localizada em Vila Velha/ES e outra em Vitória/ES, com o intuito de investigar de que maneira as tecnologias da Informação e Comunicação têm favorecido a aprendizagem dos alunos quando utilizados nos projetos educacionais interdisciplinares. A investigação se deu a partir das aulas desenvolvidas nos laboratórios de informática com as turmas de $1^{\circ}$ ao $5^{\circ}$ ano entre os anos de 2014 e 2015. Como resultado deste estudo concluiu-se que a metodologia de projetos quando aliada às tecnologias contribui significativamente na aprendizagem e autonomia dos alunos e no seu processo de formação.

\section{Introdução}

Assim como no cotidiano das pessoas as tecnologias também estão cada vez mais inseridas no cotidiano escolar. Os alunos apresentam nas escolas determinadas habilidades quanto ao uso dessas ferramentas. É desafio dos educadores o direcionamento pedagógico dos usos das Tecnologias da Informação e Comunicação (TIC) na aprendizagem.

$\mathrm{O}$ uso das tecnologias quando bem aplicados nos projetos pedagógicos contribuem para o desenvolvimento da aprendizagem, desperta o interesse do aluno, dinamiza as atividades escolares, favorece a formação de alunos críticos, capazes de analisar o contexto social no qual está inserido. Além disso, os projetos educacionais ajudam a socializar os saberes e experiências. Apenas adquirir o conhecimento sobre 
determinado tema não é o bastante, é preciso que o indivíduo possa atuar na sociedade de modo a intervir nos problemas sociais que o cercam.

Considerando a importância da informática na promoção de aquisição de novas aprendizagens, em que se utiliza para isso a metodologia de projetos, elaborados e planejados de forma interdisciplinar, visando o desenvolvimento completo do indivíduo, questiona-se: As Tecnologias da Informação e Comunicação estão sendo utilizadas na metodologia de projetos desenvolvidos por professores, alunos e profissionais do laboratório de informática de modo a contribuir de forma significativa com a aprendizagem dos alunos? Que ações são necessárias para que o uso das TIC no apoio ao desenvolvimento de projetos interdisciplinares contribua para a aprendizagem?

$\mathrm{Na}$ busca a essas respostas, foi realizada uma pesquisa em duas escolas municipais da Grande Vitória/ES, com o objetivo de investigar se o trabalho colaborativo entre os professores de sala de aula e os profissionais que trabalham nos laboratórios de informática, no desenvolvimento e aplicação dos projetos escolares com o uso das TIC, tem contribuído para a metodologia diária do professor, em especial a metodologia de projeto de aprendizagem.

Diante da nova perspectiva do uso das TIC na educação, a pesquisa se mostra relevante na medida em que agrega conhecimentos sobre a prática vivenciada por professores e alunos de escolas municipais da região da Grande Vitória ao apontar os problemas vivenciados e apresentar possíveis soluções. Propicia ainda, uma reflexão sobre a prática dos projetos educacionais interdisciplinares e o uso das tecnologias no auxilio a essa tarefa.

\section{Pedagogia de projetos}

A pedagogia de projetos mostra-se como uma alternativa que favorece essa inserção das tecnologias no processo de desenvolvimento das aprendizagens, pois possibilita a autonomia do aluno e a colaboração entre os agentes envolvidos na construção do conhecimento. É uma metodologia de trabalho educacional que organiza a maneira com que o conhecimento é construído a fim de atingir metas previamente definidas e que possa ser desenvolvido colaborativamente entre professores e alunos. Dessa maneira estabelece "relação entre teoria e prática da aprendizagem" Martins (2001).

Quando um projeto é bem construído favorece a investigação, a construção de novos conceitos e a tomada de atitudes diante de fatos da realidade. Quando a metodologia de projeto é interdisciplinar a abrangência da área de conhecimento é maior, pois as diferentes disciplinas se relacionam com o objetivo de aprofundar o conhecimento, tornando os estudos mais dinâmicos e interessantes, onde uma disciplina auxilia outra. Conforme Martins (2001, p.18),

Os projetos contribuem para que os alunos participem e se envolvam em seu próprio processo de aprendizagem e o compartilhem com outros colegas, como também exijam que o professor enfrente desafios de mudanças, diversificando e reestruturando, de forma mais aberta e flexível, os conteúdos escolares.

$\mathrm{Na}$ pedagogia de projetos o papel do aprendiz, que nunca está sozinho ou isolado, mas está sempre interagindo com o meio ao seu redor, é determinante para a construção de seu saber. O papel do professor é de estimular, mediar e criar situações de aprendizagem significativa, encaminhando o aluno rumo ao conhecimento que deseja 
construir, realizando perguntas pertinentes que fazem o aluno pensar sobre o objeto de estudo em questão.

Martins (2001) aponta as vantagens dos projetos educacionais interdisciplinares: Dar maior flexibilidade à organização dos currículos, uma vez que trabalha com conteúdos integrados das várias disciplinas, numa proposta moderna e progressista; Dar ao estudante oportunidade para refletir sobre os problemas que encontra diariamente e conduzi-lo à busca de soluções desses problemas, aproveitando os conteúdos disciplinares aprendidos em sala de aula; Favorecer a formação do raciocínio e da reflexão nos alunos, conduzindo-os a ver coisas com outros olhos e maneira diferente, aprendendo a identificá-las e relacioná-las; Estabelecer o equilíbrio entre o pensamento científico e o desenvolvimento humano pela aplicação de uma metodologia assentada no tripé: curiosidade, investigação e descoberta.

Portanto, o projeto pedagógico deve ser um direcionamento das possibilidades de caminhos a percorrer no processo de construção do conhecimento, colocando em foco as necessidades e expectativas do aprendiz. Quando aplicado dessa maneira, o projeto pedagógico contribui para a transformação do ambiente escolar em estabelecimento de aprendizagem constante, permitindo ao aluno a escolha dos objetos de aprendizagem de seu interesse, necessidade e relevância.

\title{
3. Projetos de Aprendizagem com o uso das TIC
}

Conhecimento é algo que se constrói, é interativo, dinâmico e leva ao crescimento educacional. Assim, a pedagogia de projeto aliada ao uso das TIC e suas ferramentas (vídeos, correios eletrônicos, blogs, redes sociais, entre outros) contribui para a interatividade entre os participantes desse processo, promovendo a cooperação na construção do saber.

A integração proporcionada pelas TIC na prática pedagógica promove mudanças significativas nas relações professor-aluno no que se refere aos interesses e anseios. No professor estimula a necessidade de busca de novas metodologias de ensino, demonstrando uma potencialização desse processo.

No entanto, em muitas escolas a tecnologia é vista apenas como um modismo, com o intuito de "modernizar" a escola para atender as pressões da sociedade, dos pais e dos alunos. De acordo com Kenski (2012, p. 73),

\begin{abstract}
Para que as novas tecnologias não sejam vistas como apenas mais um modismo, mas com a relevância e o poder educacional transformador que elas possuem, é preciso refletir sobre o processo de ensino de maneira global. Antes de tudo, é necessário que todos estejam conscientes e preparados para assumir novas perspectivas filosóficas, que contemplem visões inovadoras de ensino e de escola, aproveitando-se das amplas possibilidades comunicativas e informativas das novas tecnologias, para a concretização de um ensino crítico e transformador de qualidade.
\end{abstract}

Nesse contexto, o problema principal consiste em saber introduzir de forma sistemática os recursos das TIC no desenvolvimento de atividades didáticopedagógicas, buscando favorecer a aprendizagem e a melhoria nos indicadores de desempenho educacionais. "As novas tecnologias orientam para o uso de uma proposta diferente de ensino. [...] Não se trata, portanto, de adaptar as formas tradicionais de ensino aos novos equipamentos ou vice-versa" (Kenski, 2012. P. 75). 
Pesquisas recentes apontam para a importância dos projetos de aprendizagem no ambiente escolar e as vantagens atribuídas à aprendizagem do aluno. Oliveira, Ludwig e Finco (2011) realizaram uma pesquisa com alunos de $5^{\mathrm{a}}$ a $8^{\mathrm{a}}$ série de uma Escola Municipal do município de Farroupilha/RS, aplicando as TIC nas atividades interdisciplinares e constataram que é perceptível uma melhoria na auto-estima dos alunos, na sua autonomia e um aumento no interesse e no envolvimento nas atividades propostas, além de contribuir para novas aprendizagens.

Em estudo realizado numa escola pública do município de Porto Alegre sobre o uso das TIC e a metodologia dos Projetos de Aprendizagem, Corbellini e Real (2013) concluíram que o uso das tecnologias permite trazer o mundo para a sala de aula, e que ao utilizar-se da tecnologia na educação, transformações significativas acontecem, como o fato do professor deixar de ser o único detentor do saber. O conhecimento passa a estar disponível ao aluno ao alcance de um clique, o que amplia as possibilidades que vão além daquelas oferecidas pelo professor. Outro aspecto observado foi o fomento à cooperação, a autonomia, às relações, as trocas e o despertar do desejo do saber.

Os projetos e aprendizagem com uso das TIC oportunizam uma nova forma de ensinar e de aprender, quebra os paradigmas de um ensino linear, pautado em série e classificação, abrindo um leque de inúmeras possibilidades de aprendizagem. Nele os conhecimentos são construídos por meio das trocas de informações, na cooperação e colaboração entre os envolvidos, na mediação do professor, utilizando-se dos conhecimentos anteriores dos alunos.

Os trabalhos cooperativos são aqueles que permitem a comunicação entre os envolvidos. Eles incluem mecanismos de comunicação para viabilizar auxílio aos pares na realização de determinada tarefa. "O aluno em uma abordagem cooperativa de ensino, tem maior autonomia e maior grau de responsabilidade. Tem tarefas a cumprir e se expõe mais facilmente, pois sempre haverá tempo e espaço para a apresentação de suas opiniões" (Kenski, 2012, p. 125)

Esse tipo de trabalho contribui para uma formação que vai além do saber em si, ela amplia a formação do indivíduo ensinando-o a respeitar as opiniões e pensamentos alheios e a superar as diferenças, buscando resultados comuns ao grupo. $\mathrm{Na}$ aprendizagem colaborativa "o papel do professor é o de criar um contexto no qual os alunos possam produzir seu próprio material através de um ativo processo de descoberta" (Kenski, 2003, p.9).

A partir de uma pesquisa sobre como é feito o planejamento das atividades no Laboratório de Informática Educativa (LIE) em dez escolas públicas municipais de Fortaleza/CE, Nascimento et al (2011) demonstraram que há necessidade de promover momentos de integração entre professores, para que se familiarizem com o ambiente, com as tecnologias digitais e com a proposta da informática na educação. Importante que sejam oportunizados horários de planejamento no próprio laboratório de informática e encontros de formação docente para o uso dessas tecnologias.

De acordo com Kenski (2012, p. 48-49) “A diferença didática não está no uso das novas tecnologias, mas na compreensão das suas possibilidades. Mais ainda, na compreensão da lógica que permeia a movimentação entre os saberes no atual estágio da sociedade tecnológica". Ao dominar as novas tecnologias o professor será capaz de analisar criticamente programas e projetos tecnológicos impostos às escolas, que não 
tenham a qualidade educativa necessária, assim ele poderá aceitá-los, rejeitá-los ou ainda adaptá-los para que possam auxiliá-lo no momento e maneira mais adequados.

\section{Metodologia e contextualização da pesquisa}

$\mathrm{Na}$ escola localizada em Vitória/ES, as tecnologias são utilizadas como um apoio às propostas de aprendizagens desenvolvidas em sala de aula. Para utilizar o laboratório de informática o professor regente precisa fazer um agendamento prévio com o professor responsável pelo setor e apresentar o planejamento da aula ou projeto que pretende trabalhar com a turma.

Já a escola localizada em Vila Velha/ES, a partir de 2014, incluiu a tecnologia como disciplina curricular, em que as atividades desenvolvidas nas aulas são de acordo com os conteúdos curriculares propostos pela secretaria de educação do município.

Com o intuito de investigar como as TIC têm favorecido a aprendizagem dos alunos quando utilizados nos projetos educacionais interdisciplinares, foi realizado um estudo de caso de caráter comparativo dos trabalhos desenvolvidos no uso das TIC nos projetos educacionais das duas escolas. De acordo com Godoy (1995, p.25), "O estudo de caso tem se tornado a estratégia preferida quando os pesquisadores procuram responder às questões "como" e "por quê" certos fenômenos ocorrem".

A coleta dos dados foi realizada por meio de observações das aulas no laboratório de informática e aplicação de questionários a 11(onze) professores regentes do $1^{\circ}$ ao $5^{\circ}$ ano e a 2 (dois) professores de tecnologia educacional das duas escolas. Nas observações das aulas, foram analisadas as atividades realizadas pelos alunos, nesse espaço, quanto ao uso das ferramentas oferecidas pelo computador (internet, editores de texto, jogos, vídeos, entre outros) e a verificação da relação dessas atividades e ferramentas aos projetos escolares. Observou-se também a participação do aluno e a sua interação com os recursos tecnológicos, no intuito de analisar se o laboratório de informática potencializa um ambiente cooperativo em que favorece a busca e a construção de novos conhecimentos. Foram observadas as aulas de informática realizadas nos meses de fevereiro e março de 2015.

Os dados captados dos questionários foram analisados por estatística. A análise das observações foi realizada durante todo o processo de investigação, por meio de teorizações progressivas e interativas com os dados obtidos nos questionários, relacionando as informações obtidas com a revisão bibliográfica realizada.

\section{Apresentação e discussão dos resultados}

O principal aspecto analisado foi a utilização de projetos educacionais interdisciplinares nas aulas. Constatou-se que apenas uma professora não utiliza a metodologia de projetos em suas aulas, o que evidencia um reconhecimento da importância dessa metodologia para a aprendizagem significativa.

Ao relacionar o uso das Tecnologias da Informação e Comunicação nos projetos educacionais interdisciplinares, $77 \%$ dos professores regentes afirmam utilizar as TIC nos projetos e 83,3\% acreditam que elas servem de apoio para essa metodologia, contribuindo de forma significativa na aprendizagem. Embora compreendam que as TIC podem contribuir de forma significativa com a aprendizagem dos alunos, muitos não fazem uso desses recursos em suas aulas. 
Na escola de Vila Velha os professores regentes não utilizam o laboratório de informática. Justificaram que desde o ano de 2014 foi introduzida no currículo escolar, a disciplina de Tecnologia Educacional. Assim, as aulas no laboratório acontecem somente com a professora de tecnologia, enquanto os professores regentes encontram-se em planejamento. No entanto, mesmo com essa mudança curricular, alguns professores buscam combinar momentos para utilizar esse espaço quando sentem necessidade.

Por outro lado, na escola de Vitória as aulas no laboratório de informática ocorrem com a participação dos professores regentes. Os recursos tecnológicos servem de apoio aos conteúdos trabalhados em sala de aula. Apesar de poder contar com o laboratório disponível, apenas $50 \%$ dos professores utilizam esse espaço semanalmente, $17 \%$ nunca utilizaram e $33 \%$ utilizam eventualmente. É importante ressaltar que para utilizar esse espaço os professores regentes precisam agendar horário com a professora de tecnologia e apresentar um planejamento.

Na opinião dos professores regentes, as TIC auxiliam de forma significativa na metodologia de projetos: auxiliam na interdisciplinaridade; permitem trabalhar de forma mais lúdica e atualizada; possibilitam a pesquisa, a interação e o trabalho colaborativo, ampliando a produção de novos conhecimentos; despertam o interesse do aluno, que adquirem mais autonomia, desenvolvem a criatividade e o raciocínio.

Os professores da escola de Vila Velha relatam que não recebem nenhum incentivo do sistema educacional e nem orientação pedagógica para inserir os recursos tecnológicos em suas aulas. Para se atualizarem na utilização dessas novas tecnologias procuram fazer cursos, treinamentos, formações oferecidas por outras redes na qual trabalham e/ou particular. $25 \%$ dos professores nunca fizeram nenhum tipo de formação na área de tecnologia.

Os professores da escola de Vitória também não recebem orientação pedagógica para inserir atividades com utilização dos recursos tecnológicos em suas aulas, mas a maior parte deles diz receber incentivos do sistema educacional, como formações, materiais didáticos e equipamentos para uso pessoal (tablets, notbooks...), porém $25 \%$ afirmam não receber nenhum tipo de incentivo. A falta de capacitação dos professores, ou a baixa qualidade das formações oferecidas é um dos fatores que dificulta o uso das tecnologias nas atividades escolares.

Na escola de Vila Velha observa-se que a principal dificuldade encontrada pelos professores é a falta de acesso ao laboratório de informática. A política adotada pela secretaria do município de inserir as aulas de tecnologia no currículo escolar contribuiu para a ausência do professor regente nas aulas no laboratório e consequentemente a limitação dos recursos tecnológicos disponíveis, ficando como livre acesso somente a sala de vídeo, que dispõe de projetor (datashow), caixa de som e televisor.

Essa realidade vai ao encontro ao que afirma Almeida (2010), que um dos fatores que faz com que os professores não utilizem computadores na escola deve-se ao fato de se ter um único laboratório, o que é pouco para dar conta da quantidade de alunos. Isso desestimula o professor, porque ele só consegue utilizar no máximo duas vezes por semana (na escola de Vila Velha, nem uma vez). Essa falta de disponibilidade do laboratório acarreta a não cultura da integração da tecnologia com o currículo escolar. 
O planejamento conjunto com o professor de tecnologia é o segundo fator de dificuldade apontado pelos professores. $\mathrm{O}$ fato da aula de tecnologia não ser ministrada pelo professor regente contribui para a sua não participação nos planejamentos. Os professores que declararam realizar o planejamento conjunto (14\%) o fazem devido às aulas eventuais combinadas com o professor de laboratório, quando há necessidade.

$\mathrm{Na}$ escola de Vitória essa realidade é diferente, pois a maior parte dos professores regentes faz planejamento junto ao professor de informática. Desta forma garantem a organização das atividades, objetivos claros e definidos. Quanto á qualidade dos trabalhos, os professores reconhecem que os sujeitos estão envolvidos no processo de aprendizagem e o conhecimento é construído significativamente.

Para evitar o uso da máquina pela máquina é necessário desenvolver projetos interdisciplinares bem integrados com as TIC, variando as metodologias e os recursos. Daí a importância do planejamento, que deve ser bem estruturado e de acordo com o nível dos alunos. Só assim, as TIC podem favorecer um aprendizado significativo. Quando um ambiente de aprendizagem garante a troca de experiências entre professores e alunos, os sujeitos são envolvidos no desenvolvimento individual e coletivo, garantindo a construção dos saberes e a formação de cidadãos.

$43 \%$ dos professores da escola de Vila Velha disseram não participar das aulas no laboratório de informática e não opinaram quanto à qualidade do trabalho desenvolvido nessas aulas. Outros $43 \%$ responderam que as aulas são planejadas visando a construção de conhecimento e troca de experiências entre os sujeitos envolvidos. Para que o trabalho no laboratório seja de qualidade é importante a participação do professor regente nesse momento. Assim, sua ausência das aulas provocou uma avaliação negativa por parte de $14 \%$ dos professores.

A falta de equipamentos e/ou com defeito é o fator de maior dificuldade para o uso do recurso apontado pelos professores das duas escolas. Na escola de Vila Velha apenas $8 \%$ dos professores responderam que não encontram dificuldade ao usar os recursos tecnológicos, enquanto que na escola de Vitória foram 33\%. Conciliar os recursos tecnológicos com os conteúdos ministrados em sala, planejar as aulas com o professor de tecnologia e a conexão da internet lenta foram outros fatores de reclamação dos professores da escola de Vitória.

Uma quantidade considerável de professores $(31 \%)$ relatam fazer uso das TIC em uma concepção tradicional, apesar de a maioria acreditar que as tecnologias estão sendo usadas de maneira a garantir a construção do conhecimento com participação dos sujeitos envolvidos (46\%). Essa dificuldade demonstra que muitos professores não conseguiram se desvencilhar dos velhos modelos de educação e se atualizar para atender a nova geração de alunos, que é tecnológica.

$\mathrm{Na}$ análise dos resultados dos questionários aplicados aos professores de tecnologia educacional, contatou-se que tanto a professora da escola de Vitória quanto a da escola de Vila Velha fizeram curso de capacitação na área de tecnologia para exercer as atividades no laboratório de informática. Para que se tenha um uso constante e com qualidade das tecnologias na escola é preciso investir na capacitação dos professores.

Quanto às dificuldades encontradas nas aulas de tecnologia a professora da escola de Vitória apontou: Falta de equipamentos e/ou com defeito; professores regentes não possuem capacitação para utilizar as tecnologias; planejar as aulas com os 
professores regentes; falta de apoio da equipe pedagógica. Já a professora da escola de Vila Velha destacou apenas a demora no suporte e manutenção dos equipamentos.

A dificuldade em se planejar as aulas de tecnologia junto com os professores regentes deve-se ao fato dos horários para planejamento não coincidirem ou ao fato dos professores sentirem dificuldades em adequar os conteúdos trabalhados em sala com as tecnologias. Sem o apoio da equipe pedagógica orientando os trabalhos e contribuindo para que esses entraves sejam vencidos, as consequências são aulas descontextualizadas dos conteúdos de sala de aula.

$\mathrm{Na}$ escola de Vitória, a professora consegue realizar planejamentos conjuntos eventualmente e promover aulas que garantem uma ligação com os conteúdos de sala. São poucos os professores que utilizam as aulas no laboratório para desenvolver projetos de aprendizagem interdisciplinares que são estruturados em parceria e com a colaboração dos alunos.

$\mathrm{Na}$ escola de Vila Velha, embora as aulas sejam realizadas sem a presença do professor regente e que os temas das aulas sejam propostos pela Secretaria de Educação do Município, as aulas são planejadas visando atender também ao projeto institucional da escola, planejados em parceria com professores e alunos, para que se possa caminhar juntamente com as propostas de aprendizagem em que todos estão envolvidos.

Ao aliar as TIC com a metodologia de projetos, as professoras de tecnologia enumeram os muitos benefícios: "Amplia a visão do contexto e aumenta as possibilidades de desenvolvimento intelectual"; "A aprendizagem se torna significativa, no momento em que reafirmamos e aprofundamos os conceitos repassados em sala de aula"; "Os alunos compreendem que é importante a atenção e participação, pois sem entendimento de informações básicas o alcance da tecnologia torna-se limitado". Compartilharam ainda, experiências enriquecedoras de projetos interdisciplinares que desenvolveram em suas aulas (Tabela 1).

Tabela 1: TIC usadas como apoio ao desenvolvimento de projetos

\begin{tabular}{|c|c|c|}
\hline Projeto & Atividade & Recurso utilizado \\
\hline Manguezal & Releitura do manguezal & TuxPaint $^{1}$ \\
\hline Copa do mundo & $\begin{array}{l}\text { Edições de trabalhos orientados } \\
\text { para apresentação }\end{array}$ & Impress $^{2}$ \\
\hline Curtindo o diário & $\begin{array}{l}\text { Elaboração de } b \log ^{3} \text { em forma de } \\
\text { diário }\end{array}$ & $\begin{array}{l}\text { Site para criação de blog: } \\
\text { www.webnode.com.br. }\end{array}$ \\
\hline Boas energias na escola & Produção de tabelas e gráficos & $\mathrm{calc}^{4}$ \\
\hline Gazeta na sala de aula & $\begin{array}{l}\text { Leitura de textos online e reescrita } \\
\text { das reportagens. }\end{array}$ & $\begin{array}{l}\text { www.gazetaonline.com.br. } \\
\text { Editor de texto writer. } \\
\text { Dicionário online. }\end{array}$ \\
\hline Alimentação saudável & $\begin{array}{l}\text { Exibição de vídeos educativos, } \\
\text { construção de pirâmide alimentar } \\
\text { online, elaboração de textos e } \\
\text { execução de pesquisas. }\end{array}$ & $\begin{array}{l}\text { Site: www.youtube.com.br } \\
\text { Jogos de pirâmide alimentar. } \\
\text { Editor de texto writer. } \\
\text { Site: } \text { www.google.com.br. }\end{array}$ \\
\hline
\end{tabular}

Fonte: autoria própria

\footnotetext{
${ }^{1}$ Editor de imagens voltado para crianças com ferramentas para desenhar, pintar e criar formas.

2 Programa utilizado para criar, editar e exibir apresentações gráficas por meio de projetor.

${ }^{3}$ Site que permite a publicação de textos na internet sem precisar dominar linguagem de programação.

${ }^{4}$ Software que possibilita a criação e manipulação de tabelas de cálculos.
} 
Percebe-se que, embora haja alguns entraves que dificultam a realização de projetos de aprendizagem inserindo as TIC e apesar dos professores avaliarem que as aulas ainda apresentam uma concepção tradicional, muito já se tem feito nas escolas que apontam para uma realidade mais inovadora.

\section{Considerações finais}

Usar as novas tecnologias aliadas a projetos educacionais interdisciplinares é um grande desafio. Requer um movimento de mudança na maneira que se concebe os conceitos de ensinar e aprender e do papel do professor e do aluno nesse novo contexto digital.

A escola carrega ao longo dos anos uma larga experiência no ensino tradicional e grandes mudanças trazem incertezas e inseguranças para os envolvidos nesse processo. Quando se trata de inserir as novas tecnologias na metodologia de projetos as dificuldades se ampliam. Os professores demonstram rejeição, pois se sentem reféns de suas próprias limitações.

A grande diferença entre a metodologia tradicional e a metodologia de projetos é o papel do professor. Se historicamente aprendemos que cabia ao professor tomar a decisão do que devíamos aprender e aferir se o que foi aprendido era o esperado por ele, na metodologia de projetos o professor assume o papel de mediador desse processo e a decisão do que é importante aprender naquele momento é dos próprios alunos.

Nesse contexto, as tecnologias tornam-se grande aliadas ao sucesso da aprendizagem, pois elas permitem que o professor estimule a busca de informações e faça a mediação para a transformação dessas informações em análises e avaliações. Além disso, elas permitem que os alunos interajam com situações e vivências externas à sala de aula, estabelecendo relações com a realidade e proporcionam uma participação mais ativa do aluno.

Nas escolas pesquisadas, percebe-se uma iniciativa ainda tímida na modernização da prática do professor. Alguns trabalhos com projetos têm sido feitos e obtidos resultados satisfatórios, enquanto os alunos sentem-se estimulados e envolvidos com as novas descobertas. Mesmo enfrentando dificuldades na prática do uso das TIC, os professores reconhecem seu potencial no processo de ensino e aprendizagem.

Um fator que chamou atenção na pesquisa foi a falta de acesso ao laboratório de informática pelos professores regentes da escola de Vila Velha. Os estudos da área apontam para a importância da parceria professor regente/aluno/professor de tecnologia no desenvolvimento de projetos educacionais com uso das TIC, para que não sejam utilizadas com um fim em si mesmas, mas para que sejam recursos que propiciam ao aluno aprender a exercer a autonomia de sua própria aprendizagem.

O tempo destinado ao planejamento das propostas de ensino para que haja a integração das tecnologias digitais no ambiente escolar é outro fator que necessita ser discutido nas duas escolas. Planejar quando se usa metodologia de projetos interdisciplinares e as tecnologias demanda maior disponibilidade e participação de toda a comunidade escolar. A falta de cooperação entre os profissionais aliados à falta de planejamento das ferramentas mais adequadas para os objetivos propostos são complicadores que tem dificultado a eficiência desses trabalhos. Devem ser pensadas as peculiaridades de cada turma, levando-se em conta as necessidades de cada faixa etária e os objetivos que se pretende alcançar na formação do aluno. 
Conclui-se da pesquisa, que as Tecnologias da Informação e Comunicação quando bem aplicadas aos projetos educacionais contribuem significativamente à aprendizagem dos alunos e que a integração entre todos os envolvidos no projeto (professor, aluno e profissional do laboratório de informática) favorecem melhores condições de aprendizagem, pois a colaboração proporcionada pelo uso das tecnologias amplia as possibilidades de produção do conhecimento. Espera-se que as dificuldades, técnicas ou metodológicas, sejam superadas para que as tecnologias sirvam para provocar mudanças na formação individual de cada estudante.

\section{Referência Bibliográfica}

Almeida, Maria Elizabeth Bianconcini de (2010). Maria Elizabeth de Almeida fala sobre tecnologia na sala de aula. Acessado em março/2015 em http://gestaoescolar.abril.com.br/aprendizagem/entrevista-pesquisadora-puc-sptecnologia-sala-aula-568012.shtml?page $=2$.

Corbellini, Silvana; Real, Luciane Corte (2013). Tecnologias e Projetos de Aprendizagem: da necessidade ao desejo - uma construção da cidadania na/pela cooperação. Anais WIE 2013. Acessado em dezembro/2014 em http://www.brie.org/pub/index.php/wie/article/view/2631/2285.

Godoy, Arilda Schmidt (1995). Pesquisa qualitativa: tipos fundamentais. Revista de administração de empresas, v. 35, n. 3, p. 20-29. Acessado em abril/2014 em http://www.scielo.br/pdf/rae/v35n3/a04v35n3.pdf.

Kenski, Vani Moreira (2003). Aprendizagem mediada pela tecnologia. Revista Diálogo Educacional, Curitiba, v. 4, n. 10, p. 47-56.

Kenski, Vani Moreira (2012). Tecnologias e ensino presencial e a distância. Campinas, SP: Papirus.

Martins, Jorge Santos (2001). O trabalho com projetos de pesquisa: do ensino fundamental ao ensino médio. Campinas, SP: Papirus.

Nascimento, Karla Angélica S.; Lima, Mixilene Sales Santos; Freire, Raquel Santiago; Filho, José Aires de Castro (2011). Um olhar sobre as atividades dos Laboratórios de Informática Educativa das escolas municipais de Fortaleza. Anais do XXII SBIE - XVII WIE. Acessado em dezembro/2014 em http://www.br-ie.org/sbiewie2011/WIE-Trilha1/93033_1.pdf.

Oliveira, Angela Maria; Ludwig, Lucimeri; Finco, Mateus David (2011). Proposta pedagógica do uso das TICs como recurso interdisciplinar. Anais do XXII SBIE XVII WIE. Acessado em dezembro/2014 em http://www.br-ie.org/pub/index.php/ wie/article/view/1974/1733. 